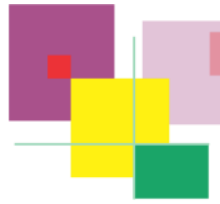

DOI: 10.20396/lil.v46i46.8661630

\title{
A CONTRIBUIÇÃO DA HISTÓRIA DAS IDEIAS LINGUÍSTICAS E DA ANÁLISE DE DISCURSO PARA O ESTUDO SOBRE EDUCAÇÃOO ESCOLAR INDÍGENA NO BRASIL
}

\section{THE CONTRIBUTION OF THE HISTORY OF LANGUAGE IDEAS AND DISCOURSE ANALYSIS FOR THE STUDY ON INDIGENOUS SCHOOL EDUCATION IN BRAZIL}

\author{
Abraão Janderson dos Santos Amaral* \\ UFPI \\ Maraisa Lopes** \\ UFPI
}

Resumo: Este artigo tem por objetivo expor o processo de articulação teóricometodológica entre a História das Ideias Linguísticas (HIL) e a Análise de Discurso Materialista (AD), que tem sido realizado por nós em pesquisas relacionadas às políticas linguísticas da Educação Escolar Indígena no Brasil. Trata-se, pois, de demonstrar os procedimentos de pesquisa utilizados $e$, nesse percurso, trazer exemplificações com base no objeto supra referido. Além disso, pretendemos discutir sobre a noção de política linguística a partir de uma perspectiva materialista, concebendo-a enquanto prática sóciopolítica e dialética relacionada com os processos ideológicos e diferindo-a de uma concepção sociologista.

Palavras-chave: História das ideias linguísticas, Análise de discurso, Política linguística.

Abstract: This paper aims to expose the process of theoretical-methodological articulation between the History of Linguistic Ideas (HLI) and the 
Materialistic Discourse Analysis (AD), which has been conducted by us in research related to the language policies of Indigenous School Education in Brazil. It is about, therefore, demonstrating the research procedures used and, this way, bringing examples based on the above-mentioned object. Besides that, we intend to discuss the notion of language policy from a materialist perspective, conceiving it as a socio-political and dialectical practice related to ideological processes and differing it from a sociologist conception.

Keywords: History of linguistic ideas, Discourse analysis, Language policy.

\section{Considerações iniciais}

No Brasil, a articulação teórica entre a Análise de Discurso (AD), de vertente materialista, e a História das Ideias Linguísticas (HIL), de origem francesa, se tornou frequente, desde o começo deste século. Em meados de 1987 e 1988, o projeto direcionado à história da ciência, coordenado por S. Auroux na Universidade de Paris VII, teve a adesão de Eni Orlandi que, na época, já havia estabelecido convênio entre Unicamp e Paris VII com o projeto "Discurso, Significação e Brasilidade". Instaurou-se, com os dois projetos, uma colaboração contínua, da qual resultou a publicação do $\mathrm{n}^{\circ} 130$ da revista Langages, em 1998 (ORLANDI, 2001a). Após essa publicação, é consolidada, em algumas universidades brasileiras, uma série de projetos, núcleos e revistas interessados em abordar a história dos saberes metalinguísticos e a constituição da língua nacional.

$\mathrm{Na}$ Universidade Federal do Piauí (UFPI), o projeto AD/HIL tem fornecido bases para realizar pesquisas relativas aos discursos sobre a língua portuguesa na $\mathrm{BNCC}^{1}$ e a institucionalização do curso de Letras/Libras no Brasil ${ }^{2}$. Além disso, a HIL e a AD tem cumprido papel fundamental para analisar as políticas linguísticas indigenistas inerentes à Educação Escolar Indígena (EEI). Isso porque a primeira teoria disponibiliza conceitos suscetíveis de apreender os fenômenos históricos, sem estigmatizá-los numa visão anacrônica, além de oferecer métodos para o entendimento histórico do âmbito extralinguístico. Já a segunda intervém na anterior, modificando sua configuração epistemológica, bem como acrescendo dispositivos de descrição e interpretação de abrangência linguístico-discursiva.

Neste artigo, são apresentados alguns desses pressupostos, de maneira conjunta; primeiramente, trataremos das concepções teóricas, 
do objeto e de sua caracterização histórica e discursiva, tendo em vista conceitos direcionados aos saberes ou discursos sobre linguagem. Em seguida, definiremos as noções acerca de políticas linguísticas, instrumentos linguísticos, legislações e diretrizes que as subjazem.

E, por fim, faremos uma série de reflexões e abordagens de procedimentos analíticos direcionados para a apreensão da dimensão histórica e discursiva dos discursos sobre a linguagem, indicando as formas de operacionalização dos mesmos.

\section{Articulação teórica, objetos e pressupostos basilares}

A História das Ideias Linguísticas (HIL), tal qual é concebida em sua articulação com a Análise de Discurso (AD), consiste no aparato teórico-metodológico direcionado para descrever e interpretar, numa perspectiva discursiva e histórica, os processos de elaboração, instrumentalização e transmissão dos saberes metalinguísticos, no decorrer do espaço-tempo (COLOMBAT et al, 2017). Nesse ínterim, colocam-se, defronte a essa prática científica, questões relativas à natureza linguística e histórica do conhecimento, na medida em que se busca compreender os discursos sobre a linguagem e a conjuntura sócio-histórico-ideológica em que esses se realizaram, na forma de instrumentos linguísticos e de políticas linguísticas.

Com esse fim, é estabelecido o seguinte objeto teórico: "seja a linguagem humana, tal como ela se realizou na diversidade das línguas; saberes se constituíram a seu respeito; este é o nosso objeto" (AUROUX, 2014a, p. 14, grifos do autor). Em outros termos, interessa à HIL os saberes sobre a linguagem que tenham se manifestado ao longo da história do conhecimento humano. Essa delimitação teórica pressupõe um tratamento diferenciado e menos valorativo em relação às ideias sobre a linguagem constituídas no período anterior ou posterior ao contexto ocidental do século XVIII, no qual se desenvolveu a concepção de cientificidade (COLOMBAT et al., 2017). Longe de um olhar normativo, analisam-se os saberes metalinguísticos em sua própria historicidade, através de procedimentos metodológicos apropriados.

Quando nos referimos ao saber metalinguístico, designamos o produto resultante da competência de utilizar-se da língua para falar da linguagem, que se configura em "uma representação consciente, aberta à transmissão tanto relativamente estabilizada quanto relativamente 
móvel, submetida, enfim, para o historiador das ideias linguísticas ao regime de historicidade variável no tempo" (COLOMBAT et al, 2017, p.49). Há, assim, uma especificidade desse objeto teórico em relação a outros, cuja diferenciação reside no fato de que ele pressupõe, em primeira instância, a aquisição de uma competência para organizar conhecimentos elementares sobre a linguagem em uma metalinguagem e, com efeito, conduz à elaboração do saber metalinguístico, suscetível de circulação discursiva e de materialização linguística e histórica.

Diferindo-nos de uma concepção segundo a qual o surgimento de do conhecimento, no decorrer do tempo, surgiria de rupturas ou revoluções, entendemos que o saber metalinguístico é contínuo, na medida em que sofre deslocamentos e incorpora, na forma de esquecimentos, os saberes anteriores para fazer emergir outros. Amostra disso é a noção de língua utilizada nos documentos oficiais regentes da Educação Escolar Indígena (EEI), cujo significado já se encontra estabilizado no imaginário social e que, apesar de estar permeado do saber antropológico, continua a carregar traços da tradição greco-latina, a exemplo da dissociação que se é feita em relação à língua, enquanto parte da cultura; e à fala, enquanto manifestação oral da língua.

Diante dos aspectos do saber metalinguístico, situamo-nos frente a um fenômeno histórico que alarga nosso horizonte de retrospecção e, ao mesmo tempo, garante sua especificidade. Contudo, se considerarmos a relação desses saberes com a luta de classes de uma determinada formação social, constatar-se-á não apenas a dimensão histórica a ser tratada, mas também as dimensões discursiva e ideológica. É nesse sentido que Orlandi (2001a) e Nunes (2008), de modo mais dialético, defendem que a abordagem discursiva permite ampliar a definição de saber metalinguístico, concebendo-o como discurso sobre a linguagem.

Conforme Orlandi (2013), proceder sobre esse terreno teórico nos traz a vantagem de tratar da história de forma integral e mostrar como "o estudo sobre a história da língua e de seu conhecimento pode nos 'falar' da sociedade e da história política da época, assim como do que resulta como ideias que se constituem e que nos acompanham ao longo de nossa história" (ORLANDI, 2013, p. 16). Nesse sentido, a contribuição da AD fornece a possibilidade de apreender a materialidade linguístico-discursiva dos saberes metalinguísticos, 
materializados em arquivos históricos, bem como permite investigar suas implicações de sentido.

$\mathrm{Na}$ perspectiva de Nunes (2008), entender os saberes metalinguísticos em sua discursividade nos conduz a não considerar transparentes os documentos nos quais eles se realizam, remetendo-os às suas condições de produção e a outros discursos de diferentes ordens a partir dos quais foram constituídos em sua especificidade.

Em se tratando da EEI, essa articulação facilita o processo de delineamento histórico das políticas linguísticas ancoradas em certos saberes oriundos do contexto estadunidense e europeu garantidos pelo Estado de Direito; e os sentidos suscitados pela assunção desses discursos em condições de produção relacionadas ao contexto jurídicoliberal e à situação enunciativa multicultural dos movimentos indígenas. Ressaltamos, entretanto, que essa articulação não pretende abordar dois objetos distintos, mas sim abarcar um único objeto teórico - os discursos metalinguísticos - sob dimensões múltiplas - as dimensões histórica, ideológica e a discursiva. E para atingir tais instâncias faz-se mister definir o que é o discurso e quais são suas propriedades teóricas.

De acordo com Pêcheux (2014a), o discurso pode ser definido como "efeitos de sentido" suscitados entre sujeitos no decorrer de sua interação linguística, sob condições de produção específicas, isto é, um complexo significativo que fornece as possibilidades de interpretação das materialidades simbólicas, a partir de determinadas condições sócio-histórico-ideológicas e enunciativas. Sendo assim, o discurso estabelece formas de mediação simbólica tanto entre o sujeito e sua exterioridade concreta e social, quanto entre a linguagem e seus processos de produção de sentidos (ORLANDI, 2003). Aliando a concepção de discurso ao saber metalinguístico, podemos afirmar, pois, que estamos lidando com efeitos de sentido relacionados à linguagem, que são realizados numa certa conjuntura.

Conforme Nunes (2006), os sentidos, por sua vez, são concebidos sempre "em relação a" e não de forma unívoca, uma vez que se ancoram em processos históricos e ideológicos que estão sempre se atualizando sob novas condições de produção e a partir de diferentes sujeitos. Sendo assim, os sentidos depreendidos da linguagem e da realidade exterior não são, segundo Pêcheux (2014b), definidos de forma independente ou autônoma: 
as palavras, expressões, proposições etc., mudam de sentido segundo as posições sustentadas por aqueles que as empregam, o que quer dizer que elas adquirem seu sentido em referência às formações ideológicas [...] nas quais essas posições se inscrevem (PÊCHEUX, 2014b, p. 146 , grifos do autor).

Nos termos de Pêcheux (2014b), os processos de significação são determinados pelas posições ideológicas de cada sujeito, dissimuladas em decorrência da naturalização produzida pela ideologia, cuja atribuição é a de mascarar o "caráter material dos sentidos" e a historicidade da língua (PÊCHEUX, 2014b). Dessa forma, a partir da ideologia, a historicidade e o caráter político dos sentidos tornam-se evidentes, de modo que os sujeitos se reconheçam como fonte da significação e não percebam seu assujeitamento face às formações ideológicas (FI) que os determinam. Para Pêcheux e Fuchs (2014), a formação ideológica constitui o "conjunto complexo de atitudes e de representações que não são nem 'individuais' nem 'universais'; mas se relacionam mais ou menos diretamente a posições de classes em conflito umas com as outras" (PÊCHEUX; FUCHS, 2014, p. 163).

A utilização do conceito de FI permite-nos entender a estruturação geral que tomam os sentidos, sobretudo, em relação aos conflitos entre a formação ideológica jurídico-liberal e a formação ideológica científica. Em concepções de língua, essas duas FIs se materializam principalmente no imaginário de unidade linguística perpassado, inclusive, no Referencial Curricular Nacional das Escolas Indígenas (RCNEI). Nele, a língua portuguesa é apresentada como unidade oficial e como condição para o exercício da cidadania (HONÓRIO, 2000), ao passo que simultaneamente se é reivindicada a diversidade concreta das línguas indígenas, compondo o confronto desigual entre dois discursos antagônicos e evidentes.

As FIs disponibilizam, assim, elementos de representação do real, assim intitulados de imaginários, uma noção que se atrela ao conceito de formações imaginárias. Conforme Pêcheux (2014a), essas dizem respeito ao fato de que, em toda formação social, existem regras de projeção que permitem demarcar os lugares ocupados por cada sujeito na sociedade, os quais "estão representados nos processos discursivos" 
(PÊCHEUX, 2014a, p.81). Sendo assim, enquanto as formações imaginárias designam projeções ideológicas de posições ocupadas por cada sujeito, os imaginários, no sentido aqui empregado, tomam a acepção segundo a qual determinados aspectos do real são representados, de acordo com a FI que os antecede.

Tomemos como exemplo as Diretrizes para a Política Nacional de Educação Escolar Indígena (DPNEEI). Nas DPNEEI, há a presença do saber metalinguístico antropológico, de natureza especulativa. Assim, vemos, constantemente, a relação entre língua e cultura, como no trecho "a língua materna de uma comunidade é parte integrante de sua cultura" (BRASIL, 1994, p. 11). Essa noção, por conseguinte, traz à tona imaginários das línguas e dos sujeitos que as falam, instituindo uma projeção distinta do sujeito indígena, ao reconhecer sua identidade e sua cultura. Há, portanto, uma mudança nas relações de força sustentadas no documento, em contraposição aos imaginários coloniais em que a posição do indígena era sempre dissociada da do europeu na perspectiva do "comportamento do selvagem" versus a "cultura do civilizado".

Nessa medida, os discursos sobre linguagem sempre encontram suas bases na coerção do complexo de FIs. O funcionamento da interpelação ideológica não se realiza, entretanto, na forma de ideias impostas abstratamente, pois sua natureza simbólica se encontra materializada em regiões de assujeitamento discursivo, intituladas de formações discursivas (FD). Nessa perspectiva, Pêcheux (2014b) as define como "aquilo que, numa formação ideológica dada, [...] determina o que pode e deve ser dito" (PÊCHEUX, 2014a, p. 147). Com efeito, a determinação operada pela FD ultrapassa a questão da imposição. Antes, designa a condição sine qua non para que haja a continuidade do discurso, por intermédio de processos discursivos.

Outrossim, os discursos e imaginários que se confluem e se confrontam em torno EEI não se concretizam de maneira autônoma, mas através de sua inserção em práticas sócio-políticas. Partindo disso, podemos compreender o processo do qual resulta os lugares de confronto entre formações ideológicas e discursos sobre a linguagem, cuja prática social se dá através do que chamamos de política linguística.

\section{Política linguística, instrumentos linguísticos e objetos analíticos}


Uma vez que lidamos com discursos sobre linguagem e línguas indígenas, bem como suas manifestações em documentos formais normatizados para todo território nacional, cumpre-nos fazer uma explicitação do papel do Estado nas formas de representação ideológica e na prática política em relação à ecologia das línguas e, consequentemente, aos sujeitos que com elas se identificam. Os estudos focados na formulação de políticas linguísticas tomam sua forma no campo das ideias linguísticas a partir da década de 1960, época em que intelectuais alinhados teoricamente às abordagens multiculturalistas e sociologistas da linguagem, tais como a Dialetologia, os estudos de Bilinguismo, a Sociolinguística etc., fortalecem a investigação de projetos de intervenção sobre línguas.

Nas palavras de Calvet (2007, p. 11), a política linguística trata da "determinação das grandes decisões referentes às relações entre as línguas e a sociedade", as quais são estabelecidas por decisões conscientes para o gerenciamento dessas instâncias. Quanto a Markke (1989), considera que "a formulação de políticas linguísticas envolve decisões concernentes ao ensino e ao uso da língua, e sua formulação cuidadosa por aqueles com poderes para fazê-la" (MARKEE apud COOPER, 1989, p. 30, tradução nossa) ${ }^{3}$. Já Spolsky (2004), de modo mais abrangente, entende que "ao estudar a política linguística, geralmente estamos tentando entender quais variáveis não linguísticas podem co-variar com as variáveis de linguagem" (SPOLSKY, 2004, p. 8 , tradução nossa) ${ }^{4}$.

Conforme os autores citados, uma vez deliberada uma política linguística, dá-se lugar ao planejamento linguístico. De acordo com Calvet (2007, p. 46), tal noção designa o ato de "implementação prática de uma política linguística", a partir de dois tipos de gestões de línguas, a que funciona in vivo, mediada e praticada pela própria população em seu dia a dia, e in vitro, cujas decisões são refletidas por especialistas em linguagem e aplicadas pelo Estado. Contudo, o autor afirma que somente este último tem o poder de fazer um planejamento e passar à fase de implementação, devido à correlação de forças políticas e à capacidade de gerir recursos humanos e econômicos.

Vemos, com base nas definições elencadas, que o campo de disciplinas interessadas em política de línguas, ancoradas no sociologismo, conduz suas reflexões a partir de pressupostos passíveis de discussão: a natureza política com a qual se lida é geralmente a que 
diz respeito aos atos político-administrativos mediados pelas instituições sociais (em especial o Estado). Com relação a essa premissa, a HIL/AD produzem deslocamentos fundamentais, visto que entendem a política como constitutiva das práticas de linguagem e não apenas como atos institucionais ou coletivos. Nesse sentido, a própria noção de política linguística toma efeitos de sentido distintos, conforme explica Orlandi (2007):

Quando falamos de Política Linguística enquanto Política de línguas, damos à língua um sentido político necessário. Ou seja, não há possibilidade de se ter língua que não esteja já afetada desde sempre pelo político. Uma língua é um corpo simbólico-político que faz parte das relações entre sujeitos na sua vida social e histórica (ORLANDI, 2007, p. 8).

A condição política é, pois, elemento sine qua non das relações entre língua, sujeito e Estado, não havendo preponderância de "grandes decisões", mas de práticas sociais emergentes em determinadas conjunturas sócio-histórico-ideológicas. Logo, a política linguística é ressignificada enquanto elemento constitutivo da linguagem e das línguas (DINIZ, 2012) e, mais ainda, enquanto conflito ideológico entre os imaginários e as condições de existência das formas material e concreta das línguas, como pode-se atestar no caso das diversas políticas linguísticas indigenistas no Brasil.

Ao longo do século XX, especialmente a partir de 1910, quando da fundação do Serviço de Proteção aos Índios (SPI), entrou em vigor no Brasil uma política linguística integracionista, pela qual o Estado pretendia "inserir", gradualmente, o sujeito ameríndio na sociedade brasileira, sendo a educação e o ensino da língua portuguesa os meios apropriados para tal fim (STAUFFER, 1959). Ainda nos anos 1960, além das tradicionais políticas de conversão católica, entra em cena o Summer Institut of Linguistic (SIL) com sua ambígua política científica, transvestida de conversão evangélica e apaziguamento de tensões territoriais entre indígenas e empresas multinacionais (ORLANDI, 2013). E por fim, a partir de 1970, irrompem os movimentos de professores indígenas que, juntamente a outros grupos sociais, 
formulam projetos educacionais voltados para os povos e suas próprias línguas (HONÓRIO, 2000).

Nessa medida, as políticas linguísticas da EEI não são compostas somente de uma relação direta e de mão única entre o governo e os sujeitos indígenas, mas de lugares afetado por diversas relações de força e discursos sobre as línguas, que se instituem de um ou outro modo e produzem efeitos de sentido para toda a sociedade. Como atesta Diniz (2012),

diferentes processos de instrumentalização e institucionalização de uma língua têm seus efeitos em termos de política linguística - mesmo quando não guardam uma relação direta com ações do Estado, e mesmo quando não são levados a cabo a partir de decisões conscientes que visem à intervenção explícita em determinadas práticas linguísticas (DINIZ, 2012, p. 16).

As políticas linguísticas são, assim, resultantes de processos sóciohistórico-ideológicos que instituem imaginários e, consequentemente, discursos e práticas sobre as línguas, cujas manifestações materiais podem tomar diversas formas - documentos oficiais, instrumentos linguísticos, projetos científicos etc. Ademais, no interior dessa estruturação, são perpassadas as relações de força, cristalizadas ou em disputa, que subsistem no modo de produção vigente. É por isso que, para Orlandi (2001a), o conjunto de arquivos constituintes das políticas linguísticas "são um excelente observatório da constituição dos sujeitos, da sociedade e da história" (ORLANDI, 2001a, p. 9).

Sendo assim, as políticas linguísticas transcendem o planejamento ou a planificação. Spolsky (2004, p. 8, tradução nossa) admite, inclusive, que "a política linguística existe mesmo quando não foi explicitada ou estabelecida pela autoridade" ${ }^{5}$, assim como o ato de gestão dessa política que se dá geralmente, mas "não necessariamente [...], em um documento formal". Obviamente que a política à qual ele se refere difere teoricamente da que se é empregada aqui, mas se levarmos à cabo o fato de que a PL instaura uma intervenção sobre as línguas e, acima de tudo, se entendermos a política como instância indissociável da vida humana, temos por resultado uma concepção 
materialista-dialética dos conflitos linguísticos e de como estes se consolidam socialmente.

Para demonstrar isso, tomemos como exemplo as políticas linguísticas do Brasil colonial, no século XVIII. Antes que Marquês de Pombal pensasse em instituir a língua portuguesa como única língua legítima, já havia sido posta em prática, há muito tempo, uma política de extermínio de indígenas e, como resultado, uma política linguística de glotocídio, especialmente, das línguas do grupo Jê, das demais não pertencentes a grupos gerais, e, posteriormente, das línguas gerais e as do grupo Tupi. De tal sorte que este consiste, ao invés das reformas oficiais pombalinas, o fator mais determinante para o estabelecimento da língua portuguesa em detrimento das línguas gerais (ANJOS, 2012).

É nessa medida que o genocídio de uma comunidade linguística se configura, também, em uma política linguística de extinção de suas línguas e de seus processos de identificação. Em suma, as políticas linguísticas, do modo como a tratamos, referem-se às práticas sóciopolíticas tomadas, por sujeitos, em relação às línguas, em determinado espaço enunciativo, no qual se entrecruzam e se conflitam imaginários ideológicos, ancorados em condições de produção que, por sua vez, concretizam-se em discursos e saberes metalinguísticos manifestos em textos diversos.

Ao considerarmos os trabalhos realizados no Brasil, veremos pesquisas que trabalham com manuais de redação (LOPES, 2012), com provas de proficiência e livros didáticos (DINIZ, 2008), com bases curriculares de ensino de língua portuguesa e cadernos das Olimpíadas de Língua Portuguesa (SILVA, 2017), entre outros, concebendo-os na perspectiva analítica dos instrumentos linguísticos, isto é, tecnologias linguísticas destinadas à aquisição de certas habilidades em relação às línguas e à linguagem (AUROUX, 2014a). Quanto à EEI, também entendemos que os referenciais curriculares, a exemplo do Referencial Curricular de Escolas Indígenas (1998), se caracterizam como tal, na medida em que objetivam municiar professores e formadores de capacidades reflexivas relacionadas a certo conjunto de saberes.

Para além disso, a prática teórica da HIL/AD tem por especialidade entender os instrumentos linguísticos conjuntamente a atos legislativos, arquivos históricos, documentos formais etc., enquanto objetos analíticos. Na concepção aqui adotada, "o objeto empírico (analítico) é o texto", sendo este último distinguido como "unidade complexa de 
significação" (ORLANDI, 2012, p. 28). Assim, constatamos que os discursos sobre a linguagem e as línguas se manifestam em diversos textos, dos quais se destacam como elementos passíveis de análise "instrumentos de jurisdição da língua, aspectos da oficialização de seu ensino, processos de censura, de regulamentação, acordos etc." (ORLANDI, 2001a, p. 17). A partir de cada tipo de arquivo, é possível apreender parte do processo político e linguístico de uma época, tendo em vista que, enquanto as jurisdições oficializam uma prática, os instrumentos medeiam-nas com os sujeitos afetados por essa sistematização linguística.

\section{Por uma apreensão histórico-discursiva}

Uma vez explicitado o aparato teórico da articulação entre HIL e $\mathrm{AD}$, faremos, doravante, discussões a respeito do método através do qual se busca apreender a materialidade histórica dos momentos de elaboração, instrumentalização e transmissão dos saberes metalinguísticos, articulados aos processos de constituição, formulação e circulação semântica desses saberes. Com isso, evocaremos elementos direcionados à reconstituição de discursos sobre a linguagem, em contraposição à ilusão historicista de que os fatos históricos poderiam ser descritos de maneira neutra e transparente.

Ao analisar, historicamente, o saber metalinguístico, a primeira problemática se dá com relação à sua elaboração, isto é, o momento em que começa a se configurar sua forma no espaço-tempo de uma sociedade. Contrariando-nos à perspectiva idealista, consideramos que as ideias linguísticas são produtos históricos e não ocorrem espontaneamente em certas conjunturas, muito menos emergem de condições universais.

Tendo isso em vista, Auroux (2014a) e Colombat et al. (2017) estabelecem como primeiro princípio para o historiador das ideias linguísticas a necessidade de observação dos fatos extralinguísticos que incidiram sobre os saberes metalinguísticos, o que implica o conhecimento geral das problemáticas sociais, políticas, econômicas que permearam a época em questão. Para Colombat et al. (2017), coloca-se, diante disso, a

necessidade de uma ancoragem social e institucional [...], pois não se pode esquecer o 
contexto no qual as teorias (ou os saberes) emergem. Algumas dentre elas são estreitamente ligadas ao desenvolvimento histórico particular [...]. Sobre épocas mais próximas, é necessário conhecer o contexto social, a organização universitária, a criação de escolas novas [...], o recrutamento dos professores, o funcionamento das revistas etc. (COLOMBAT et al., 2017, p. 41).

Remetendo tais pressupostos à Educação Escolar Indígena (EEI), põe-se um horizonte de retrospecção intricado aos fatores sociais, políticos e institucionais das quase três décadas de elaboração e consolidação de um modelo de política linguística particular. Durante esse período, podemos constatar que a participação social de indígenas passou por uma nova fase de politização, sobretudo por conta da nova fase desenvolvimentista a pôr em risco suas condições de vida. Ainda, no ano de 1991, tinha-se no Brasil mais de 40 movimentos sociais, oficialmente organizados por indígenas, missionários e pesquisadores ${ }^{6}$; congressos e encontros anuais voltados à educação própria dos povos indígenas ${ }^{7}$; a instrumentalização de instrumentos linguísticos, tais como o livro didático escrito na língua tikuna em 1987; a formação de professores indígenas, autônoma e em conjunto com pesquisadores universitários; e diversos protestos indigenistas contra a construção de barragens, as precárias políticas públicas de saúde da FUNAI, entre outras reivindicações ${ }^{8}$.

Conforme vemos nos exemplos, a elaboração do saber encontra-se articulada aos fatores históricos do seu tempo, à tradição metalinguística que lhe antecede e ao processo de instrumentalização das línguas e dos conhecimentos linguísticos, em instrumentos tecnológicos apropriados. Em outros termos, a história do saber metalinguístico também nos induz à "necessidade de fazer a história de um instrumento linguístico em seu conjunto" (COLOMBAT et al., 2017, p. 42). Para tanto, cumpre-nos fazer o movimento analítico de interpretar os conceitos, as regras, os procedimentos e as teorias em geral, em articulação com seu contexto de surgimento, de instrumentalização e, por fim, de transmissão; afinal, conforme Auroux (2008, p. 126), "não há saber sem transmissão". Com efeito, ao analisarmos a transmissão, temos como foco as transferências 
tecnológicas, a recepção e as políticas linguísticas de disseminação dos saberes metalinguísticos.

Em se tratando das políticas linguísticas da EEI, o momento histórico de maior transmissão dos saberes referidos se deu logo após o começo do século XXI, principalmente sob o mandato do governo progressista de Luiz Inácio Lula. Entre 2004 e 2008, o apoio financeiro dado pelo Ministério da Educação (MEC) e pela Secretaria de Educação Continuada, Alfabetização e Diversidade (SECADI) possibilitou a edição de mais de 84 materiais didáticos, publicações em cerca de 38 línguas indígenas e a produção de 128 livros de autoria indígena (PALADINO; ALMEIDA, 2012). Essa política linguística de transmissão de instrumentos linguísticos é, portanto, um fato histórico importante para a história do modelo educacional indígena.

Em suma, é diante dos processos de elaboração, instrumentalização e transmissão do saber metalinguístico que o historiador das ideias linguísticas se defronta, devendo levar em conta tanto os fatos históricos extralinguísticos quanto a materialidade dos instrumentos linguísticos em que se consolida e se transmite o conhecimento sobre língua e linguagem. Entretanto, nem a história e nem os textos são transparentes em seu sentido, já que são mediados por processos discursivos e ideológicos. É por entender esse fato que a base fornecida por uma teoria materialista do discurso torna-se importante.

A análise de discurso materialista concebe os processos discursivos a partir do funcionamento político da linguagem, colocando-a face à história e ao sujeito. Nesse sentido, a AD toma a noção marxista de ideologia, criada por Althusser (1980) e desenvolvida por Pêcheux (2014b) e Orlandi (2003), para determinar a relação do homem com sua realidade social e material. Nas palavras daquele, "a ideologia representa a relação imaginária dos indivíduos com suas condições reais de existência" (ALTHUSSER, 1980, p. 77). Isso implica dizer que o homem não representa a realidade de forma direta, mas a interpreta através da ótica imaginária do que já definimos anteriormente por FI.

Partindo dessa premissa, Orlandi (2003) adverte que a noção de ideologia coloca em xeque a transparência da atividade interpretativa da história e da linguagem, uma vez que recusa uma suposta leitura direta da história, fazendo-a pela mediação discursiva. Com efeito, isso nos leva a questionar a dupla abordagem da HIL, o contexto extralinguístico e os instrumentos linguísticos, e ressignificá-los no tipo 
de enfoque que, primeiramente, não separe de forma estanque história e linguagem.

Sob essa perspectiva, cabe-nos entender a relação do contexto histórico e dos instrumentos linguísticos de forma dialética, enquanto dois objetos discursivos que culminam em conhecimentos sobre a linguagem. Assim, enquanto a HIL disponibiliza teoria e método para abarcar a dimensão concreta da história dos saberes e dos instrumentos linguísticos, a AD trata dos processos discursivos e ideológicos que resultam dessa articulação.

Para Orlandi (2001b), a produção de sentidos ocorre a partir de três eixos: a constituição, a formulação e a circulação. Segundo a autora, a constituição está no nível histórico-ideológico da linguagem, na origem dos sentidos; a formulação diz respeito à atualização dos sentidos a partir de condições de produção; e a circulação consiste na disseminação do texto, através das instituições sociais e das próprias atividades de interação. Cada um desses processos implica na estabilização de dizeres, no complexo com dominante intitulado de interdiscurso, e a cristalização dos sentidos, que resultam na hegemonia de determinada memória discursiva.

Segundo Mariani (1996), a memória discursiva repousa na dialética entre a repetição e a regularização, isto é, no constante processo de retomada do discurso que, simultaneamente, acaba resultado na sua cristalização - sempre que a memória social é mobilizada pelos sujeitos ou pelas instituições sociais ela passa por deslocamentos. Por conseguinte, Orlandi (2013) afirma que a memória discursiva "tem relações complexas com o saber discursivo, ou seja, com o interdiscurso, que é a memória irrepresentável, que se constitui ao longo de toda uma história de experiência de linguagem" (ORLANDI, 2013, p. 12). A partir disso, os sentidos permanecem em constante relação com a historicidade, intricada à memória discursiva.

Consoante aos pressupostos de Pêcheux (2014b), o interdiscurso tende a dissimular-se na forma de intradiscurso, deixando marcas visíveis dos outros dizeres na superfície linguística. Nas palavras do autor, "o intradiscurso enquanto 'fio do discurso' do sujeito, é, a rigor, um efeito do interdiscurso sobre si mesmo, uma 'interioridade' inteiramente determinada como tal 'do exterior"' (PÊCHEUX, 2014b, p. 154, grifos do autor). Nos discursos sobre linguagem, emergentes nos documentos oficiais da EEI, a operacionalização do conceito de 
intradiscurso permite isolar determinadas sentenças, em que se retoma explicitamente uma lei, um termo científico ou uma definição, possibilitando, assim, proceder reflexões sobre as implicações de sentido e as formas de determinação ideológica às quais as políticas linguísticas foram submetidas.

Por exemplo, na parte de instrumentalização do ensino de línguas, o RCNEI conduz uma proposição no limiar do discurso indireto e das aspas (há também línguas indígenas que os linguistas chamam de “línguas isoladas") (BRASIL, 1998, p.115), pela qual se deixa trazer à tona tanto a propriedade do linguista, quanto a sua própria formasujeito. A despeito da possibilidade múltipla de deslizamentos semânticos que suscita o sintagma línguas isoladas, demonstra-se o efeito de antecipação que interdita a historicidade do discurso, segundo o qual certas línguas indígenas estariam em estado de isolamento e, por outro lado, relaciona-o ao saber linguístico-comparativo, cuja sistematicidade discursiva se refere às línguas como não pertencentes a famílias linguísticas gerais.

A categoria do intradiscurso traz, portanto, a possibilidade de deslinearizar as proposições linguísticas, de modo a adentrar na anterioridade dos sentidos, abarcando, assim, o estágio de formulação discursiva. Segundo Orlandi (2001b), a fase de concretização da memória e do interdiscurso só ocorrem, contudo, por intermédio das condições de produção do discurso, que abarca tanto o contexto sóciohistórico-ideológico quanto a situação enunciativa imediata em que se realizam os discursos.

Por fim, cumpre-nos destacar o processo a partir do qual os discursos se consolidam em memória, a saber: a circulação discursiva. De acordo com Dias (2018, p. 33), a circulação é "o ângulo de entrada no processo de produção dos sentidos", dado ao fato de que um sentido somente se torna existente, quando encontra bases sócio-históricas onde fincar-se. Essas bases, por conseguinte, só encontram lastro da memória discursiva se obtiverem uma circulação efetiva, através da superestrutura ideológica de uma formação social.

Se relacionarmos ao contexto das políticas linguísticas da EEI, o processo de circulação discursiva pode ser visto sob a ótica das instituições universitárias e educacionais. Ao ser promulgada, em 2008, a Lei 11.645/08, que institui a obrigatoriedade do ensino da cultura e da história dos povos indígenas, pôs-se em circulação memórias 
discursivas ameríndias, cuja consolidação se daria através das práticas educacionais do país. Contudo, constata-se que o modo de circularização desses sentidos não foi suficiente para se sobrepor à memória hegemônica, tendo em vista que, no âmbito político, social e histórico, as bases materiais desses sentidos não se constituíram.

\section{Considerações Finais}

Ao longo da exposição feita neste artigo, discutimos sobre o objeto teórico - os saberes e os discursos sobre a linguagem -, bem como os conceitos necessários para apreendê-lo - ideologia, formações ideológicas, formação discursiva etc. Além disso, fizemos a explicitação dos objetos analíticos - os instrumentos linguísticos e demais textos enquanto materializações de saberes -, e do modo através do qual eles se apresentam - as políticas linguísticas.

Diante dos pressupostos apresentados, demonstramos como a articulação entre HIL e $\mathrm{AD}$ pode fornecer o aparato teóricometodológico necessário para analisar, historicamente, os processos de elaboração, instrumentalização e transmissão dos saberes metalinguísticos, articulados aos processos de constituição, formulação e circulação discursiva. Por fim, mostramos que, seguindo tais princípios norteadores, temos buscado compreender tanto as políticas linguísticas da EEI, quanto os conflitos políticos que subjazem a relação entre sujeitos indígenas e Estado brasileiro.

\section{Referências bibliográficas}

ALTHUSSER, Louis. Ideologia e aparelhos ideológicos de Estado. Lisboa: Editorial Presença/Martins Fontes, $3^{\mathrm{a}}$ ed. 1980.

ANJOS, Marcelo Alessandro Limeira dos. Marcas toponímicas em solo piauiense: seguindo as trilhas das águas. Tese. Doutorado em Linguística. Belo Horizonte: Universidade Federal de Minas Gerais, Faculdade de Letras Programa de Pós-Graduação em Estudos Linguísticos, 2012.

AUROUX, Sylvain. A revolução tecnológica da gramatização. Trad. Eni P. Orlandi. Campinas, SP: Editora da Unicamp, $3^{\text {a }}$ ed. 2014. BRASIL. Ministério da Educação. Diretrizes para a Política Nacional de Educação Escolar Indígena. Brasília, DF: MEC/SEF/DPEF, 2ª ed. 1994 
BRASIL. Ministério da Educação. Referencial Curricular Nacional para as Escolas Indígenas. Ministério da Educação e do Desporto, Secretaria de Educação Fundamental. Brasília, DF: MEC/SEF, 1998. CALVET, Louis-Jean. As políticas linguísticas. São Paulo: Parábola/IPOL, 2007.

COLOMBAT, Bernard; FOURNIER, Jean-Marie; PUECH, Christian. Uma história das ideias linguísticas. Trad. Jacqueline Léon; Marli Quadros Leite. São Paulo: Contexto, $1^{\mathrm{a}}$ ed, 2017.

COOPER, Robert Leon. Language planning and social change. Cambridge, CB: Cambridge University Press, 1989.

DIAS, Cristiane. Análise do discurso digital: sujeito, espaço, memória e arquivo. Campinas, SP: Pontes Editores, 2018.

DINIZ, Leandro Rodrigues Alves. Mercado de línguas: a instrumentalização brasileira do português como língua estrangeira. Dissertação. Mestrado em Linguística. Campinas: Universidade Estadual de Campinas, 2008.

DINIZ, Leandro Rodrigues Alves. Política linguística do Estado brasileiro na contemporaneidade: a institucionalização de mecanismos de promoção da língua nacional no exterior. Tese. Doutorado) em Linguística. Campinas: Universidade Estadual de Campinas, Instituto de Estudos da Linguagem, 2012. HONÓRIO, Maria Aparecida. Espaço enunciativo e educação escolar indígena: saberes, políticas, línguas e identidades. Tese. Doutorado em Linguística. Campinas: Universidade Estadual de Campinas, 2000 LOPES, Maraísa. Folha: do Manual ao Jornal ou do Jornalístico ao Pedagógico. Tese. Doutorado em Linguística. Campinas: Universidade Estadual de Campinas, Instituto de Estudos da Linguagem, 2012.

MARIANI, Bethania Sampaio Corrêa. O comunismo imaginário: práticas discursivas da imprensa sobre o PCB (1922 1989). Tese. Doutorado em Linguística. Campinas: Universidade Estadual de Campinas, Instituto de Estudos da Linguagem, 1996.

NUNES, José Horta. Dicionários no Brasil: análise e história. Campinas, SP: Pontes Editores; São Paulo, SP: Fapesp, 2006.

NUNES, José Horta. "Uma articulação da análise de discurso com a história das ideias linguísticas". In: Letras, Santa Maria, v. 18, n. 2, p. 107-124, jul./dez, 2008.

ORLANDI, Eni Puccinelli. "Apresentação". In: (Org.). História das ideias linguísticas: construção do saber metalinguístico e 
constituição da língua nacional. Campinas, SP: Pontes; Cáceres, MT: Unemat Editora. p. 7-20, 2001a.

ORLANDI, E. P. Discurso e texto: formulação e circulação dos sentidos. Campinas, SP: Pontes Editores, 2001b.

ORLANDI, E. P. Análise de Discurso: princípios e procedimentos. Campinas, SP: Pontes, $4^{\mathrm{a}}$ ed, 2003.

ORLANDI, E. P. "Apresentação". In:

(Org.). Política

linguística no Brasil. Campinas, SP: Pontes Editores. p. 7-10, 2007.

ORLANDI, E. P. Discurso e leitura. São Paulo: Cortez, 9a ed, 2012.

ORLANDI, E. P. Língua e conhecimento linguístico: para uma história das ideias no Brasil. São Paulo: Cortez Editora, $2^{a}$ ed, 2013.

PALADINO, Mariana; ALMEIDA, Nina Paiva. Entre a diversidade e a desigualdade: uma análise das políticas públicas para a educação escolar indígena no Brasil dos governos Lula. Rio de Janeiro: Contra Capa Livraria; LACED/Museu Nacional/UFRJ, 2012.

PÊCHEUX, Michel. "Análise Automática do Discurso (1969)". In: GADET, Françoise; HAK, Tony (Orgs.). Por uma análise automática do discurso: uma introdução à obra de Michel Pêcheux. Campinas, SP: Editora da Unicamp, $5^{\text {a }}$ ed. p. 59-158, 2014a.

PÊCHEUX, Michel; FUCHS, Catherine. "A propósito da Análise Automática do Discurso: atualização e perspectivas (1975)". In: GADET, Françoise; HAK, Tony (orgs.). Por uma análise automática do discurso: uma introdução à obra de Michel Pêcheux. Campinas, SP: Editora da Unicamp, $5^{\text {a }}$ ed. p. 159-250, 2014.

PÊCHEUX, Michel. Semântica e discurso: uma crítica à afirmação do óbvio. Campinas, SP: Editora da Unicamp, $5^{\mathrm{a}}$ ed., 2014b.

RODRIGUES, Aryon. "Os estudos de linguística indígena no Brasil". In: Revista de Antropologia, v. 11, n. 1 e 2, p. 9-21, 1963.

SILVA, Eunice Gomes da. Políticas linguísticas e a prática discursiva no instrumento linguístico. Dissertação. Mestrado em Linguística. Porto Velho, RO: Universidade Federal de Rondônia, 2017.

SPOLSKY, B. Language policy. Cambridge: Cambridge University Press, 2004.

STAUFFER, David Hall (1959). “Origem e fundação do serviço de proteção aos índios”. Revista de história, n. 37, jan./mar, 1959. 


\section{Notas}

* Mestrando em Linguística pela Universidade Federal do Piauí (UFPI), bolsista da CAPES/Brasil e integrante do Núcleo de Estudos e Pesquisas em Análise do Discurso (NEPAD) e do Núcleo de Estudos em Linguagem, Tecnologia e Educação (NELTE).

** Professora Adjunta da Universidade Federal do Piauí (UFPI), Mestra e Doutora em Linguística pela Universidade Estadual de Campinas (UNICAMP). Possui PósDoutorado em Educação de Surdos pela Flagler College (Florida/USA).

${ }^{1}$ LOPES, M.; ARAUJO, M. P. S. A Língua Portuguesa na Base Nacional Comum Curricular (BNCC): um olhar sob a articulação entre a História das Ideias Linguísticas e a Análise de Discurso. In: COSTA, M. T. de A.; SAMPAIO, E. M. L.; ALBORNOZ, O. M.. (Orgs.). Os Caminhos da Formação Docente. Teresina: Edufpi, 2018, p. 142159.

${ }^{2}$ LOPES, M. A institucionalização do curso de licenciatura em Letras-Libras no Brasil: língua, sujeitos e sentidos". In: Língua e instrumentos linguísticos, Campinas, SP, n. 42, p. 57-71, jul-dez, 2018.

3 "Language policy-making involves decisions concerning the teaching and use of language, and their careful formulation by those empowered to do so" (MARKEE apud COOPER, 1989, p. 30).

4 "In studying language policy, we are usually trying to understand just what nonlanguage variables co-vary with the language variables" (SPOLSKY, 2004, p. 8).

5 "language policy exists even where it has not been made explicit or established by authority" (SPOLSKY, 2004, p. 8).

${ }^{6}$ Povos indígenas no Brasil: 1991-1995. Ed. Carlos Ricardo. São Paulo: Instituto Socioambiental, 1996.

7 SILVA, Rosa Helena Dias da. A autonomia como valor e articulação de possibilidades: o movimento dos professores indígenas do Amazonas, de Roraima e do Acre e a construção de uma política de educação escolar indígena. In: Cadernos Cedes, 1999, ano 9, no 49, dez., p. 62-75.

${ }^{8}$ PORANTIM. Em Roraima, não às colônias. Brasília, DF, 1988, ano 10, $\mathrm{n}^{\text {o }} 105$, jan./fev. 